\title{
Factors associated with chronic musculoskeletal pain in patients with chronic kidney disease
}

\author{
Heng-Jung Hsu 1,2,3, Chiung-Hui Yen ${ }^{4}$, Kuang-Hung Hsu ${ }^{5}$, I-Wen Wu ${ }^{1,3}$, Chin-Chan Lee ${ }^{1,3}$, Ming-Jui Hung ${ }^{2,3,6}$, \\ Chiao-Yin Sun ${ }^{1,3}$, Chia-Chi Chou ${ }^{1,3}$, Yung-Chih Chen ${ }^{1,3}$, Ming-Fang Hsieh ${ }^{1,3}$, Chun-Yu Chen ${ }^{1,3}$, Chiao-Ying Hsu ${ }^{1,3}$, \\ Chi-Jen Tsai ${ }^{1,3}$ and Mai-Szu Wu $\mathbf{W}^{1,2,3,7,8^{*}}$
}

\begin{abstract}
Background: Chronic musculoskeletal (MS) pain is common in patients with chronic kidney disease (CKD) undergoing haemodialysis. However, epidemiological data for chronic MS pain and factors associated with chronic MS pain in patients with early- or late-stage CKD who are not undergoing dialysis are limited.

Method: A cross-sectional study to evaluate the prevalence of chronic MS pain and factors associated with chronic MS pain in patients with early- and late-stage CKD who were not undergoing dialysis, was conducted. In addition, the distribution of pain severity among patients with different stages of CKD was evaluated.

Results: Of the 456 CKD patients studied, 53.3\% $(n=243 / 456)$ had chronic MS pain. Chronic MS pain was independently and significantly associated with hyperuricemia as co-morbidity, as well as with the calcium $x$ phosphate product levels. In CKD patients with hyperuricemia, chronic MS pain showed a negative, independent significant association with diabetes mellitus as a co-morbidity (odds ratio: $0.413, p=0.020$ ). However, in the CKD patients without hyperuricemia as a co-morbidity, chronic MS pain showed an independent significant association with the calcium $\times$ phosphate product levels (odds ratio: 1.093, $p=0.027$ ). Furthermore, stage-5 CKD patients seemed to experience more severe chronic MS pain than patients with other stages of CKD.

Conclusion: Chronic MS pain is common in CKD patients. Chronic MS pain was independently and significantly associated with hyperuricemia as co-morbidity, and with the calcium $\times$ phosphate product levels in early- and late-stage CKD patients who were not on dialysis.
\end{abstract}

Keywords: Chronic pain, Musculoskeletal pain, Chronic kidney disease, Hyperuricemia

\section{Background}

The worldwide prevalence of chronic kidney disease (CKD) continues to increase [1]. CKD patients develop many complications, which lead to a high risk of comorbidities and mortality [2-4].Therefore, two issues are important for healthcare professionals caring for CKD patients: (1) prolonging the life span and (2) improved quality of life of patients.

CKD patients have a poor quality of life [5]. This may be attributed to the underlying disease or to the complications associated to CKD. The Dialysis Outcomes and

\footnotetext{
* Correspondence: maiszuwu@gmail.com

${ }^{1}$ Department of Nephrology, Chang Gung Memorial Hospital, 222, Mai-Chin

Road, Keelung 20401, Taiwan

${ }^{2}$ The Graduate Institute of Clinical Medical Sciences, Chang Gung University

Medical College, Taoyuan School of Medicine, Taipei, Taiwan

Full list of author information is available at the end of the article
}

Practice Patterns Study (DOPPS), a large, international, observational study, demonstrated that quality-of-life indicators from SF-36 were associated with differential survival and morbidity [6]. Body pain is one of the most important qualitative parameters for evaluating patients' quality of life [7]. To improve quality of care provided to CKD patients, it is important to understand and relieve body pain.

It has been reported that $82 \%$ of CKD patients undergoing dialysis had chronic pain, [8] and $35-70 \%$ of patients had moderate to severe chronic pain [9]. Chronic pain is common in CKD patients [10], especially in patients with end-stage renal disease (ESRD) [11]. Musculoskeletal (MS) pain is the most common symptom of chronic pain syndromes in ESRD patients [8]. Few studies have focused on chronic pain in early-stage CKD patients.

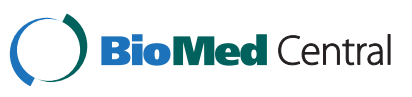


Despite the understanding of prevalence and risk factors associated with chronic MS pain in CKD patients undergoing dialysis, the epidemiologic data for factors associated with chronic MS pain in early- and late-stage CKD patients who are not on dialysis, are limited. In addition, information about the prevalence of nonsteroidal anti-inflammatory drugs (NSAID) or Chinese herbs used for pain relief in CKD patients is also limited. The aims of this study were to determine the prevalence of chronic MS pain in CKD patients and to identify the factors associated with chronic MS pain.

\section{Methods}

\section{Patients}

Pre-dialysis CKD patients who visited an outpatient clinic at the Nephrology Department of Chang Gung Memorial Hospital at Keelung, from March 2006 to July 2007, were recruited for the study. Patients satisfying the following criteria were included in this study consecutively: between 18 to 80 years old, and with no spontaneous improvement or progression of renal disease in the 3 months prior to the start of the study. Patients with acute illness requiring hospital admission in the past 3 months, cancer without remission, or who were unwilling to participate in the trial were excluded from the study. CKD was defined as the presence of persistent proteinuria, or a decreased estimated glomerular filtration rate (eGFR) of $<90 \mathrm{~mL} / \mathrm{min}$ per $1.73 \mathrm{~m}^{2}$ [determined by the CKD Epidemiology Collaboration (CKD-EPI) creatinine equation], in two separate measurements within an interval of 3 months [12]. In accordance with the National Kidney Foundation/Dialysis Outcomes Quality Initiative (NKF/DOQI) classification system, these patients were classified into stages $1,2,3,4$, or 5 for descriptive purposes. A total of 456 patients who provided informed consent were enrolled into the study (Figure 1). This study complies with the Declaration of Helsinki and was approved by the Ethics Committee of the Institutional Review Board at Chang Gung Memorial Hospital. The study was conducted at the CKD centre of the Chang Gung Memorial Hospital, Keelung, Taiwan.

\section{Study design}

All eligible patients were carefully interviewed to identify primary disease and current medications. At the time of the visit, we also checked the patients' blood pressure and performed laboratory tests. Chronic MS pain was evaluated by the Community Oriented Program for the Control of Rheumatic Diseases (COPCORD) questionnaire [13]. For patients with MS pain, pain was assessed using a visual analogue scale (VAS), with a range of $0 \mathrm{~mm}$ (no pain) to $100 \mathrm{~mm}$ (very painful), after which the patients were examined by a rheumatologist to confirm the information and characterize MS pain

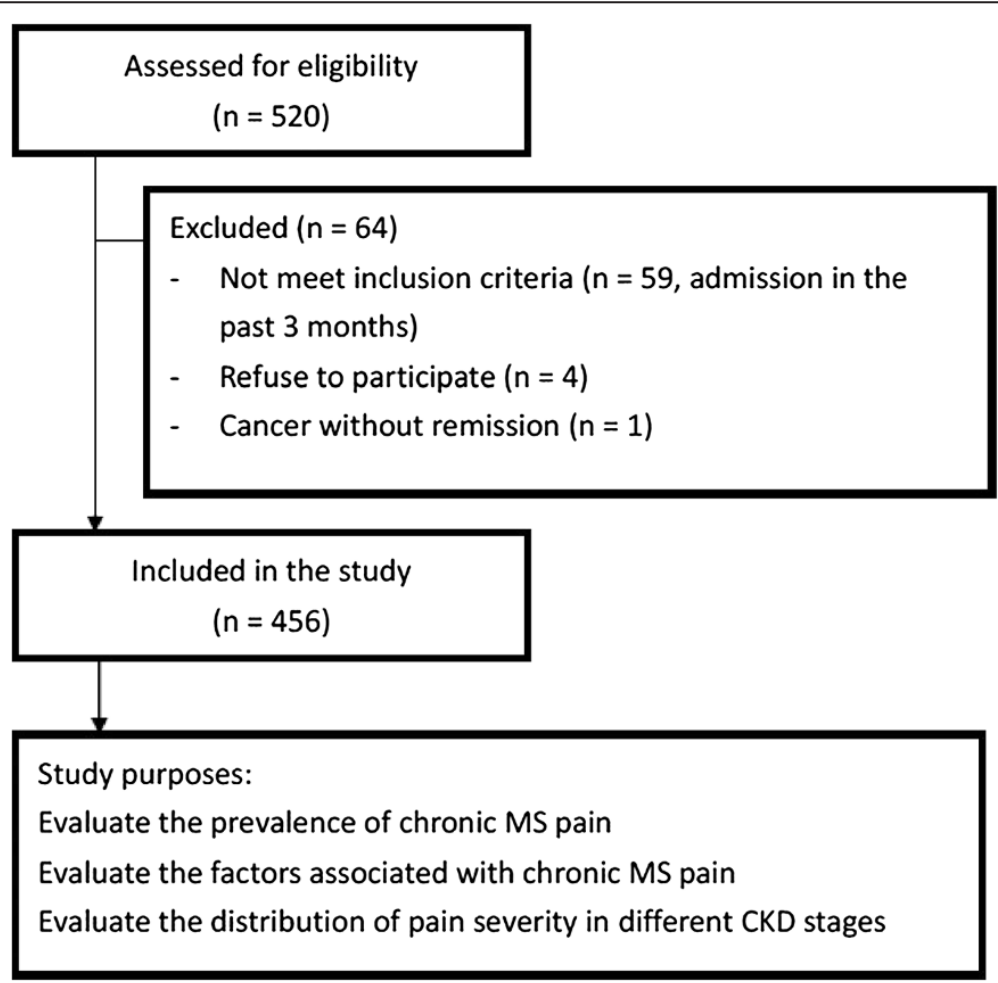

Figure 1 Flow chart indicates patient enrolment. 
symptoms. For the calculation of prevalence and for all other analyses, chronic MS pain was defined as nontraumatic MS pain for a VAS score of $>1$ for more than 3 months [8]. Pain severity categories were defined in this study as follows: VAS pain score of $30 \mathrm{~mm}$ or less, mild pain; VAS pain score of $31 \mathrm{~mm}$ to $69 \mathrm{~mm}$, moderate pain; and VAS pain score of $70 \mathrm{~mm}$ or more, severe pain. This categorization is based, in part, on the findings of Collins et al. [14].

Basic demographic data were collected, including information on age, gender, nutrition status (body mass index [BMI] and waist circumference), history of smoking, alcohol and betel nut consumption, current use of NSAIDs or Chinese herbal medicines, and the presence of diabetes, hypertension, coronary artery disease (CAD), peripheral arterial disease (PAD), congestive heart failure (CHF), stroke, hyperuricemia, systemic lupus erythematosus (SLE), urolithiasis, polycystic kidney disease (PKD), rheumatoid arthritis (RA), spondylarthropathies, spine osteoarthritis (OA), and back pain. Current use of diuretics or allopurinol was also collected. Baseline haematological and biochemical data of these patients were also collected. Smoking was defined as the consumption of more than 10 cigarettes per day for at least one year. Alcohol use was defined as daily consumption of more than $80 \mathrm{mg}$ of alcohol/day for more than one year. Current use of NSAIDs was defined by self-reported use of ibuprofen, naproxen, sulindac, piroxicam, indomethacin, tolmetin, or diclofenac (with brand names and combination formulas identified) daily or nearly every day, for the last 30 days. Current use of Chinese herbs was defined by self-reported use of any Chinese herb daily or nearly every day, for the last 30 days. Diabetes mellitus was defined as a fasting glucose level $\geq 126 \mathrm{mg} / \mathrm{dL}$ or use of any hypoglycaemic medication. Hypertension was considered to be present if the patient was on antihypertensive medicine, or if blood pressure was $>140 / 90 \mathrm{~mm} \mathrm{Hg}$. The presence of CAD was confirmed by coronary angiography, and CHF was diagnosed on the basis of the Framingham criteria for heart failure [15]. PAD was defined based on either the results of peripheral Doppler analysis, or a history of amputation. Stroke was diagnosed by clinical symptoms and the results of imaging studies. Hyperuricemia was considered if the patient was on medicine for uric acid control, or if blood uric acid level was $>8.0 \mathrm{mg} / \mathrm{dL}$. SLE was defined as per the eleven criteria by the American Rheumatism Association. The presence of urolithiasis was defined by kidney echo report or previous history of renal stone removal. The presence of PKD was defined by kidney echo report. The presence of RA was defined by the 2010 ACR/EULAR Rheumatoid Arthritis Classification Criteria [16]. The presence of spondylarthropathy was defined by the European Spondylarthropathy Study
Group criteria for spondylarthropathy [17]. Spine OA was defined by clinical history, findings on physical examination, and radiographic findings suggested by rheumatologists.

\section{Laboratory measurements}

Full laboratory profiles were obtained. The laboratory parameters included levels of blood urea nitrogen, serum creatinine (Scr), haemoglobin, albumin, calcium $(\mathrm{Ca})$, phosphate $(\mathrm{P})$, intact parathyroid hormone (iPTH), total cholesterol, triglycerides, uric acid, and high-sensitivity C-reactive protein (hs-CRP). Serum creatinine levels were assessed by spectrophotometric analysis using a modified kinetic Jaffe reaction.

\section{Statistical analysis}

Descriptive statistics were expressed as means with standard deviation or percentage frequency, as appropriate. All variables were tested for normal distribution by a Kolmogorov-Smirnov test. The Student's t-test or MannWhitney U test was applied to compare means of continuous variables. Categorical data were tested using the chi-square test. Binary logistic regression was appropriately used to test the factors associated with chronic MS pain. To identify independent associations, stepwise multivariate regression analysis was used, and variables including age, gender, and $p<0.05$ in the univariate analysis were selected. All analyses were performed by using the commercially available statistics software, SPSS version 15.0 for Windows.

\section{Results}

\section{Characteristics of the study population}

Mean age of the patients was $63.3 \pm 14.1$ years and $42.5 \%(n=194 / 456)$ of patients were male. The NSAID and Chinese herb use by CKD patients was around $7.8 \%$ $(\mathrm{n}=40 / 456)$, and $9.6 \%(\mathrm{n}=44 / 456)$, respectively. Approximately $30.7 \%(n=140 / 456)$ of patients had DM as a co-morbidity (Table 1 ). With respect to CKD stage, a large proportion of patients were stage 1 (28.3\%), stage 2 (24.1\%), and stage $3(24.8 \%)$ CKD, whereas a small proportion of patients were stage $4(17.8 \%)$ and stage 5 (5\%) CKD (Table 2). Among the CKD patients studied, $53.3 \%$ (243/456) had chronic MS pain.

\section{Chronic MS pain and pain severity in different CKD stages} CKD patients were divided into three groups: early CKD (CKD stage 1-2), CKD stage 3-4, and CKD stage 5, in order to compare the percentage of patients with chronic MS pain between groups. It was found that similar prevalence of chronic MS pain was noted in early CKD, CKD stage $3-4$, and CKD stage 5 [CKD stage $1-2$ vs. CKD stage $3-4$ vs. CKD stage 5: $49.4 \%(n=118 / 239)$ 
Table 1 Baseline characteristics classified according to the presence of chronic musculoskeletal (MS) pain

\begin{tabular}{|c|c|c|c|c|}
\hline & All patients $n=456$ & No chronic MS pain $n=213$ & Chronic MS pain $n=243$ & $\mathbf{p}$ \\
\hline Age $(y)$ & $63.3 \pm 14.1$ & $62.4 \pm 14.5$ & $64.6 \pm 13.5$ & 0.09 \\
\hline Male (n, \%) & $194(42.5 \%)$ & $64(30.0 \%)$ & $130(53.5 \%)$ & $<0.001^{*}$ \\
\hline Body mass index $\left(\mathrm{Kg} / \mathrm{m}^{2}\right)$ & $25.5 \pm 3.9$ & $25.0 \pm 3.4$ & $26.3 \pm 4.3$ & $0.001^{*}$ \\
\hline Waist (cm) & $89.9 \pm 10.9$ & $87.8 \pm 10.2$ & $93.2 \pm 11.2$ & $0.003^{*}$ \\
\hline Smoking (n, \%) & $181(39.7 \%)$ & $89(41.8 \%)$ & $92(37.8 \%)$ & 0.754 \\
\hline Alcohol use $(n, \%)$ & $131(28.7 \%)$ & $65(30.5 \%)$ & $66(27.2 \%)$ & 0.990 \\
\hline Betel nut use (n, \%) & $26(5.7 \%)$ & $8(3.8 \%)$ & $18(7.4 \%)$ & 0.078 \\
\hline NSAID use $(n, \%)$ & $40(7.8 \%)$ & $16(7.5 \%)$ & $20(8.2 \%)$ & 0.854 \\
\hline Chinese herb use (n, \%) & $44(9.6 \%)$ & $22(10.3 \%)$ & $22(9.1 \%)$ & 0.822 \\
\hline \multicolumn{5}{|l|}{ Co-morbidity } \\
\hline $\mathrm{DM}(\mathrm{n}, \%)$ & $140(30.7 \%)$ & $75(35.2 \%)$ & $65(26.7 \%)$ & $0.034^{*}$ \\
\hline Hypertension (n, \%) & $286(62.7 \%)$ & $124(58.2 \%)$ & $162(66.7 \%)$ & 0.059 \\
\hline CAD $(n, \%)$ & $35(7.6 \%)$ & 19 (8.9\%) & $16(6.5 \%)$ & 0.312 \\
\hline $\operatorname{PAD}(n, \%)$ & $2(0.4 \%)$ & $1(0.5 \%)$ & $1(0.4 \%)$ & 0.935 \\
\hline $\mathrm{CHF}(\mathrm{n}, \%)$ & $13(2.9 \%)$ & $7(3.2 \%)$ & $6(2.4 \%)$ & 0.465 \\
\hline Stroke $(n, \%)$ & $19(4.2 \%)$ & $7(3.2 \%)$ & $12(4.9 \%)$ & 0.429 \\
\hline Hyperuricemia (n, \%) & $226(49.6 \%)$ & $54(25.5 \%)$ & $172(71.0 \%)$ & $<0.001^{*}$ \\
\hline $\operatorname{SLE}(n, \%)$ & $2(0.4 \%)$ & $1(0.5 \%)$ & $1(0.4 \%)$ & 0.935 \\
\hline Urolithiasis (n, \%) & 15 (3.3\%) & $8(3.8 \%)$ & 7 (2.9\%) & 0.502 \\
\hline $\operatorname{PKD}(n, \%)$ & $1(0.2 \%)$ & $1(0.5 \%)$ & $0(0 \%)$ & 0.372 \\
\hline RA $(n, \%)$ & $3(0.7 \%)$ & $2(0.9 \%)$ & $1(0.4 \%)$ & 0.723 \\
\hline Spondylarthropathies $(n, \%)$ & $0(0 \%)$ & $0(0 \%)$ & $0(0 \%)$ & 1.000 \\
\hline Spine OA (n, \%) & $3(0.7 \%)$ & $0(0 \%)$ & $3(1.2 \%)$ & 0.372 \\
\hline Back pain $(n, \%)$ & $48(10.5 \%)$ & $1(0.5 \%)$ & $48(19.8 \%)$ & $<0.001^{*}$ \\
\hline Diuretics use (n, \%) & $63(13.8 \%)$ & $27(12.7 \%)$ & $36(14.8 \%)$ & 0.454 \\
\hline Allopurinol use (n, \%) & $213(46.7 \%)$ & $50(23.5 \%)$ & $163(67.1 \%)$ & $<0.001^{*}$ \\
\hline \multicolumn{5}{|l|}{ Blood pressure } \\
\hline Systolic pressure $(\mathrm{mm} \mathrm{Hg})$ & $133 \pm 19$ & $130 \pm 18$ & $135 \pm 19$ & $0.006^{*}$ \\
\hline Diastolic pressure $(\mathrm{mm} \mathrm{Hg})$ & $73 \pm 10$ & $73 \pm 10$ & $74 \pm 11$ & 0.631 \\
\hline
\end{tabular}

Notes: Values expressed as mean \pm SD or percent.

Abbreviations: MS: musculoskeletal, NSAID: non-steroid anti-inflammatory drug, CKD: chronic kidney disease, DM: diabetes mellitus, CAD: coronary artery disease, PAD: peripheral arterial disease, CHF: congestive heart failure, SLE: systemic lupus erythematosus, PKD: polycystic kidney disease, RA: rheumatoid arthritis, OA: osteoarthritis.

*Statistical significance based on the chi-square test for categorical variables, and t test for continuous variables.

vs. $58.2 \%(\mathrm{n}=113 / 194)$ vs. $52.2 \%(\mathrm{n}=12 / 23), \mathrm{p}=0.411]$ (Figure 2).

In CKD patients with chronic MS pain, severe pain accounted for $58 \%(\mathrm{n}=141 / 243)$ of chronic MS pain, moderate pain about $28.4 \%(n=69 / 243)$, and mild pain only accounted for $15.6 \%(n=38 / 243)$ of chronic MS pain. Mild chronic MS pain was noted in $17.8 \%(n=21 / 118)$ of CKD patients with stage $1-2$ disease, $13.3 \%(n=15 / 113)$ of CKD patients with stage $3-4$ disease, and $16.7 \%(n=2 / 12)$ of CKD patients with stage 5 disease $(\mathrm{p}=0.594)$. Moderate chronic MS pain was noted in $28 \%(n=33 / 118)$ of CKD patients with stage $1-2$ disease, $31.9 \%(n=36 / 113)$ of CKD patients with stage 3-4 disease, and $0 \%(n=0 / 12)$ of CKD patients with stage 5 disease $(\mathrm{p}<0.001)$. Severe chronic MS pain was found in $54.2 \%(n=64 / 118)$ of CKD patients with stage $1-2$ disease, $54.9 \%(n=62 / 113)$ of CKD patients with stage $3-4$ disease, and $83.3 \%(n=10 / 12)$ of CKD patients with stage 5 disease $(\mathrm{p}<0.001)$.

\section{Observed differences between CKD patients with chronic MS pain and no chronic MS pain}

Compared with patients who experienced no chronic MS pain, those who reported chronic MS pain were more likely to be male, have a higher BMI and waist circumference, higher systolic blood pressure, and were less likely to have DM as a co-morbidity. In particular, 
Table 2 Laboratory parameters classified according to the presence of chronic musculoskeletal (MS) pain

\begin{tabular}{|c|c|c|c|c|}
\hline & All patients $n=456$ & No chronic MS pain $n=213$ & Chronic MS pain $n=243$ & $p$ \\
\hline \multicolumn{5}{|l|}{ Serum parameters } \\
\hline BUN (mg/dL) & $8.4 \pm 3.4$ & $8.6 \pm 3.6$ & $8.3 \pm 3.1$ & 0.019 \\
\hline $\mathrm{Scr}(\mathrm{mg} / \mathrm{dL})$ & $1.5 \pm 1.1$ & $1.4 \pm 1.1$ & $1.6 \pm 1.1$ & 0.119 \\
\hline $\mathrm{eGFR}\left(\mathrm{mL} / \mathrm{min} / 1.73 \mathrm{~m}^{2}\right)$ & $65 \pm 34$ & $68 \pm 36$ & $63 \pm 31$ & 0.107 \\
\hline CKD stage & & & & 0.074 \\
\hline $1(n, \%)$ & $129(28.3 \%)$ & 77 (36.2\%) & $52(21.4 \%)$ & \\
\hline $2(n, \%)$ & $110(24.1 \%)$ & $44(20.7 \%)$ & $66(27.2 \%)$ & \\
\hline $3(n, \%)$ & $113(24.8 \%)$ & $49(23.0 \%)$ & $64(26.3 \%)$ & \\
\hline $4(n, \%)$ & $81(17.8 \%)$ & $32(15.0 \%)$ & $49(20.2 \%)$ & \\
\hline $5(n, \%)$ & $23(5.0 \%)$ & $11(5.2 \%)$ & $12(4.9 \%)$ & \\
\hline Haemoglobin (g/dL) & $11.8 \pm 2.1$ & $11.4 \pm 2.1$ & $12.4 \pm 2.1$ & $0.010^{*}$ \\
\hline Albumin (g/dL) & $3.9 \pm 0.5$ & $3.9 \pm 0.6$ & $3.9 \pm 0.5$ & 0.882 \\
\hline $\mathrm{Ca}(\mathrm{mg} / \mathrm{dL})$ & $9.2 \pm 0.7$ & $9.3 \pm 0.5$ & $9.2 \pm 0.8$ & 0.631 \\
\hline$P(m g / d L)$ & $3.9 \pm 0.8$ & $3.8 \pm 0.7$ & $4.0 \pm 0.9$ & 0.222 \\
\hline $\mathrm{Ca} \times \mathrm{P}\left(\mathrm{mg}^{2} / \mathrm{mL}^{2}\right)$ & $32.3 \pm 13.4$ & $30.7 \pm 13.5$ & $34.1 \pm 13.3$ & $0.039^{*}$ \\
\hline iPTH (g/mL) & $62.1 \pm 55.1$ & $62.2 \pm 54.5$ & $62.0 \pm 56.0$ & 0.964 \\
\hline Cholesterol (mg/dL) & $193.6 \pm 38.7$ & $196.1 \pm 45.8$ & $189.3 \pm 23.2$ & 0.586 \\
\hline Triglycerol (mg/dL) & $116.2 \pm 65.6$ & $120.3 \pm 84.0$ & $111.2 \pm 35.0$ & 0.699 \\
\hline Uric acid (mg/dL) & $5.4 \pm 2.1$ & $5.5 \pm 2.1$ & $5.3 \pm 2.1$ & 0.294 \\
\hline $\mathrm{hsCRP}(\mathrm{mg} / \mathrm{L})$ & $4.6 \pm 11.8$ & $4.25 \pm 13.3$ & $4.96 \pm 9.4$ & 0.535 \\
\hline
\end{tabular}

Notes: Values expressed as mean \pm SD or percent.

Abbreviations: MS: musculoskeletal, BUN: blood urea nitrogen, eGFR: estimated glomerular filtration rate, Ca: calcium, P: phosphate, Ca $\times$ P: product of calcium and phosphate, iPTH: intact parathyroid hormone, hs-CRP: high-sensitivity $C$ reactive protein.

${ }^{*} \mathrm{p}<0.05$ ( $\mathrm{p}$ values are based on Student $t$ test for analysis of continuous variables).

chronic MS pain in CKD was related to hyperuricemia and back pain co-morbidities. One hundred seventy two patients $(76.1 \%, 172 / 226)$ who had hyperuricemia had chronic MS pain, but only 71 patients $(30.1 \%, 71 / 230)$ without hyperuricemia had chronic MS pain $(\mathrm{p}<0.001)$ (Figure 3). Higher haemoglobin levels (chronic MS pain

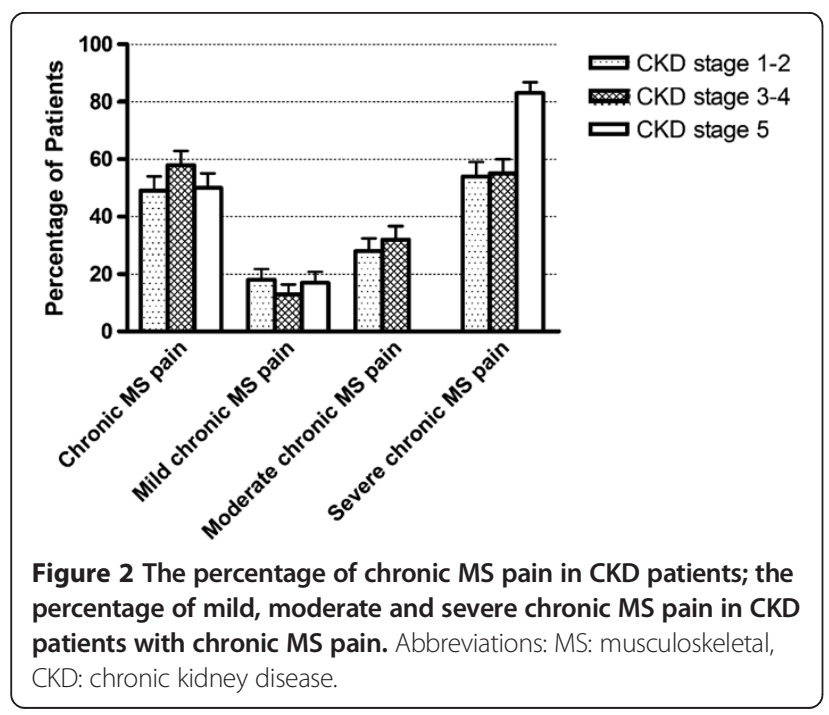

vs. no chronic MS pain: $12.4 \pm 2.1$ vs. $11.4 \pm 2.1 \mathrm{~g} / \mathrm{dL}$, $\mathrm{p}=0.010$ ) and Calcium $\times$ phosphate product (chronic MS pain vs. no chronic MS pain: $34.1 \pm 13.3$ vs. $30.7 \pm$ $\left.13.5 \mathrm{mg}^{2} / \mathrm{mL}^{2}, \mathrm{p}=0.039\right)$ were also linked with the presence of chronic MS pain. Chronic MS pain was not

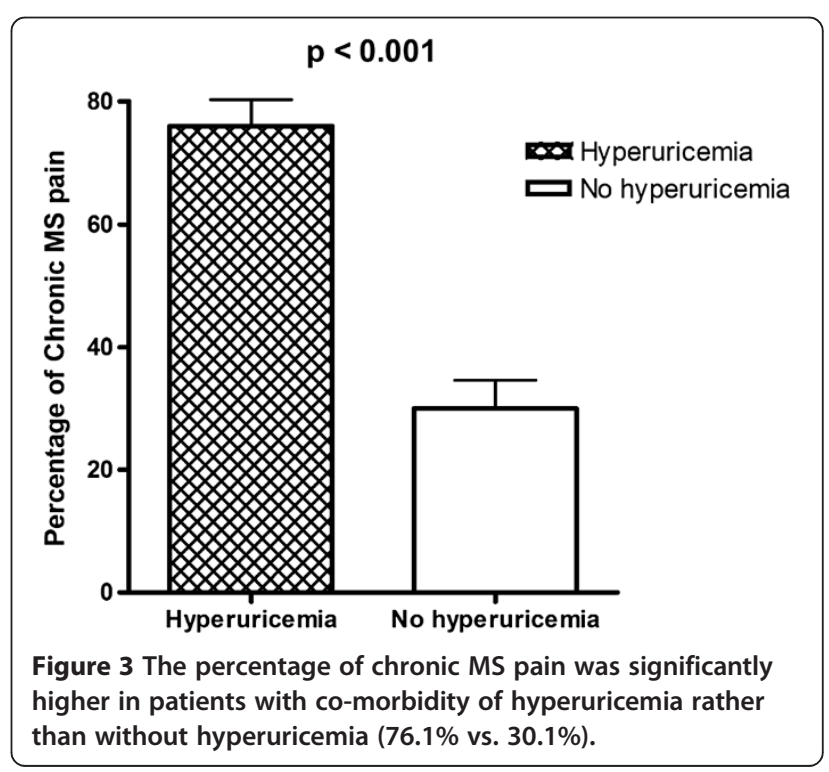


associated with age, smoking, alcohol/betel nut consumption, or co-morbidities such as hypertension, CAD, PAD, CHF, stroke, SLE, urolithiasis, PKD, RA, spondylarthropathies, spine OA, and diuretics use. In particular, there was no significant difference between current NSAID and Chinese herb use in patients with and without chronic MS pain (NSAID: $8.2 \%$ vs. $7.5 \%, \mathrm{p}=0.854$; Chinese herb: $9.1 \%$ vs. $10.3 \%, p=0.822)$. The presence of chronic MS pain was also not associated with renal function (BUN and Scr, eGFR, CKD stage), albumin, Ca, P, iPTH, cholesterol, triglycerides, uric acid, or hs-CRP.

\section{Factors associated with chronic MS pain by binary logistic regression analysis}

In this particular study, univariate analysis indicated that chronic MS pain was significantly associated with male gender, higher BMI, co-morbidity of hyperuricemia and back pain, higher systolic blood pressure, higher haemoglobin levels, higher Calcium $\times$ phosphate product, and less co-morbidity of DM. However, after multivariate analysis, chronic MS pain was only positively and independently, significantly associated with hyperuricemia and a higher Calcium $\times$ phosphate product, whereas male gender, BMI, co-morbidity of back pain and DM, systolic blood pressure, and haemoglobin level lost significance (Table 3). CKD patients were then subgrouped into patients with or without hyperuricemia as co-morbidity. In CKD patients with hyperuricemia, multivariate analysis indicated that only DM was negatively associated with chronic MS pain (odds ratio: 0.413, $\mathrm{p}=0.02$ ), but the calcium $\times$ phosphate product lost significance. However, in CKD patients without hyperuricemia, multivariate analysis showed that the calcium $\times$ phosphate product was independently and significantly associated with chronic MS pain (odds ratio: 1.093, $\mathrm{p}=0.027$ ).

\section{Discussion}

The mechanisms associated with chronic MS pain in CKD patients are multi-factorial. The present study enrolled mostly early CKD patients, and for the first time focused on chronic MS pain in this population. The findings demonstrated that chronic MS pain was independently and significantly associated with hyperuricemia and the product of calcium and phosphate levels. In CKD patients with hyperuricemia, chronic MS pain was negatively, independently, and significantly associated with the presence of DM. However, in CKD patients without hyperuricemia, chronic MS pain was positively, independently, and significantly associated with the product of the calcium and phosphate levels. Furthermore, CKD stage 5 patients seemed to suffer from more severe chronic MS pain compared to other stage CKD patients.
These findings suggest that co-morbidity of hyperuricemia may be one of the major co-morbidities that contribute to chronic MS pain in CKD patients after adjustment of other confounders. This finding may account for the high association between hyperuricemia and CKD [18]. Hyperuricemia could be a consequence of impaired kidney function, diuretic therapy, or oxidative stress [19]. Therefore, it is not surprising that the co-morbidity of hyperuricemia is associated with chronic MS pain. However, the results demonstrated that there was no significant difference in uric acid levels between CKD patients with and without chronic MS pain. This finding may confirm that normal serum uric acid level at the onset of CKD does not exclude an acute gouty attack [20]. Adequate uric acid medical control for chronic MS pain patients with hyperuricemia may also explain the similar uric acid levels in the study patients with or without chronic MS pain.

Chronic pain may be caused by various factors. This study only focused on MS pain and excluded other origins of chronic pain, such as neuropathic pain. The possible sources of chronic MS pain are gout, renal bone disease, and ischemic bone pain. The results showed that the calcium $\times$ phosphate product levels were significantly associated with chronic MS pain. Renal bone disease is a common complication of CKD. Imbalance of calcium and phosphate, vitamin D deficiency, and hyperparathyroidism are considered to cause renal bone disease [21]. However, in this study, patients with chronic MS pain had similar serum calcium, phosphate, and iPTH levels as those patients without chronic MS pain. This suggests that renal bone disease may not be the cause of chronic MS pain in the CKD patients under study. The calcium $\times$ phosphate product levels had been found to correlate with vascular calcification [22]. Therefore, vascular calcification-related micro-angiopathy and ischemic bone pain may explain why this product was strongly associated with chronic MS pain, especially in patients without hyperuricemia. Golan et al. [11] found that higher serum calcium and iPTH levels were independently associated with chronic pain in haemodialysis patients. The differences in the study populations between CKD patients pre- and post-dialysis may explain these different findings. However, these results together suggest that the calcium-phosphate imbalance is a crucial factor for chronic MS pain in CKD patients.

Diabetic nephropathy is a common complication of diabetes mellitus. In the present study, it was found that $30.7 \%$ of patients had DM as co-morbidity. This study found that patients with chronic MS pain were less likely to have DM than those with no chronic MS pain $(26.7 \%$ vs. $35.2 \%$, Table 1). In multivariate analysis, it was found that the co-morbidity of DM was negatively associated with chronic MS pain in CKD patients with hyperuricemia 
Table 3 Factors associated with chronic MS pain: univariate and multivariate analyses

\begin{tabular}{|c|c|c|c|c|c|c|}
\hline & $\begin{array}{l}\text { Univariate } \\
\text { Odds ratio }\end{array}$ & $\begin{array}{l}95 \% \text { confidence } \\
\text { interval }\end{array}$ & $\mathrm{p}$ & $\begin{array}{l}\text { Multivariate } \\
\text { Odds ratio }\end{array}$ & $\begin{array}{l}95 \% \text { confidence } \\
\text { interval }\end{array}$ & $\mathbf{p}$ \\
\hline \multicolumn{7}{|l|}{ All patients } \\
\hline Age $(y)$ & 1.002 & $0.985-1.018$ & 0.913 & & & \\
\hline Male gender & 2.295 & $1.562-3.374$ & $<0.001$ & & & \\
\hline Body mass index $\left(\mathrm{Kg} / \mathrm{m}^{2}\right)$ & 1.092 & $1.037-1.151$ & 0.001 & & & \\
\hline Co-morbidity of DM & 0.908 & $0.603-1.368$ & 0.644 & & & \\
\hline Co-morbidity of hyperuricemia & 7.167 & $4.655-11.034$ & $<0.001$ & 8.235 & $2.129-31.852$ & $0.002^{*}$ \\
\hline Co-morbidity of back pain & 85.808 & $11.722-628.114$ & $<0.001$ & & & \\
\hline Systolic blood pressure (mmHg) & 1.015 & $1.004-1.026$ & 0.007 & & & \\
\hline Haemoglobin (g/dL) & 1.256 & $1.050-1.503$ & 0.013 & & & \\
\hline $\mathrm{Ca} \times \mathrm{P}\left(\mathrm{mg}^{2} / \mathrm{mL}^{2}\right)$ & 1.226 & $1.044-1.520$ & 0.010 & 1.028 & $1.008-1.131$ & $0.022^{*}$ \\
\hline \multicolumn{7}{|c|}{ Patients with co-morbidity of hyperuricemia } \\
\hline Age (y) & 0.985 & $0.961-1.011$ & 0.258 & & & \\
\hline Male gender & 2.080 & $0.964-4.486$ & 0.062 & & & \\
\hline Body mass index $\left(\mathrm{Kg} / \mathrm{m}^{2}\right)$ & 1.093 & $0.981-1.194$ & 0.057 & & & \\
\hline Co-morbidity of DM & 0.481 & $0.235-0.981$ & 0.044 & 0.413 & $0.196-0.815$ & $0.020^{\#}$ \\
\hline Co-morbidity of back pain & 8.995 & $0.651-18.143$ & 0.998 & & & \\
\hline Systolic blood pressure (mmHg) & 1.011 & $0.992-1.031$ & 0.248 & & & \\
\hline Haemoglobin (g/dL) & 1.415 & $1.016-1.971$ & 0.040 & & & \\
\hline $\mathrm{Ca} \times \mathrm{P}\left(\mathrm{mg}^{2} / \mathrm{mL}^{2}\right)$ & 0.994 & $0.937-1.054$ & 0.835 & & & \\
\hline \multicolumn{7}{|c|}{ Patients without co-morbidity of hyperuricemia } \\
\hline Age (y) & 1.020 & $0.983-1.042$ & 0.076 & & & \\
\hline Male gender & 0.958 & $0.548-1.676$ & 0.881 & & & \\
\hline Body mass index $\left(\mathrm{Kg} / \mathrm{m}^{2}\right)$ & 1.027 & $0.948-1.113$ & 0.515 & & & \\
\hline Co-morbidity of DM & 1.505 & $0.845-2.679$ & 0.165 & & & \\
\hline Co-morbidity of back pain & 6.182 & $0.353-17.313$ & 0.998 & & & \\
\hline Systolic blood pressure (mmHg) & 1.013 & $0.997-1.029$ & 0.107 & & & \\
\hline Haemoglobin (g/dL) & 1.085 & $0.842-1.398$ & 0.528 & & & \\
\hline $\operatorname{Ca} \times P\left(\mathrm{mg}^{2} / \mathrm{mL}^{2}\right)$ & 1.083 & $1.012-1.159$ & 0.021 & 1.093 & $1.010-1.179$ & $0.027^{\#}$ \\
\hline
\end{tabular}

*p from logistic regression adjusted for age, male gender, body mass index, co-morbidity of diabetes, hyperuricemia, and back pain, systolic blood pressure, serum haemoglobin, and product of calcium and phosphate levels.

\#p from logistic regression adjusted for age, male gender, body mass index, co-morbidity of diabetes, and back pain, systolic blood pressure, serum haemoglobin, and product of calcium and phosphate levels.

Abbreviations: MS, musculoskeletal; DM, diabetes mellitus, $C A \times P$, product of calcium and phosphate.

but not in CKD patients without hyperuricemia. One possible explanation is that there is a negative association between co-morbidity of DM and hyperuricemia. However, in the present study it was found that there was no significant association between DM and hyperuricemia. Moreover, several studies have found high prevalence of gout in patients with Type 2 diabetes [23,24]. Choi et al. found that hyperuricemia is a risk factor for diabetes mellitus [25]. Moreover, Lai et al. found that gout and type 2 diabetes mellitus shared the most common genetic factors, which explains why there existed a mutual interdependent effect on higher incidences [26]. This may also be due to diabetic neuropathy. Previous studies have shown that pain-inhibiting neuropathy caused by glucose metabolism dysfunction may hide osteoarthritis pain and delay diagnosis of osteoarthritis [27]. Moreover, silent ischemia with less chest pain during acute coronary syndrome was significantly higher in diabetic patients, probably due to cardiac autonomic neuropathy [28]. Consequently, it is possible that diabetic neuropathy in diabetic CKD patients may inhibit or mask chronic MS pain. This may explain the finding of diabetes as a protective factor from chronic MS pain in CKD patients with hyperuricemia.

The study found that patients with chronic MS pain had a similar prevalence of NSAIDs or Chinese herbal 
medication use as those patients without chronic MS pain. In our study, there was no difference in use of NSAIDs or Chinese herbal medication between patients with hyperuricemia and without hyperuricemia. One possible explanation regarding the lack of association between NSAIDs use in CKD patients with pain may be due to our centre's policy to reduce the use of NSAIDs in patients with chronic MS pain. Our CKD education provides CKD patients with information on protecting renal function, including better blood pressure control and avoidance of NSAIDs and Chinese herbal medication use. There was a significantly lower rate of NSAIDs use $(7.8 \%)$ in our CKD study patients with chronic MS pain as compared to the report of Pham et al. (23.2\%) [29]. This may be the reason why our study patients had lower prevalence of NSAIDs use and Chinese herbal medication. Another explanation is that CKD patients in nephrology clinics were usually reminded of avoiding NSAIDs agents in order to protect their kidney function.

The present study revealed that $53.3 \%$ patients had chronic MS pain, with a mean eGFR around $65 \mathrm{ml} / \mathrm{min}$. However, Cohen et al. [10] reported that $69 \%$ of CKD patients with eGFR around $33.4 \mathrm{~mL} / \mathrm{min}$ experience pain. The difference in results may be due to the definition of pain duration. The present study focused on chronic MS pain lasting for more than 3 months. However, Cohen et al. [10] defined pain duration on the basis of the pain experienced by the patients in the past month. Besides, the present study patients are 100\% Asian, whereas $74 \%$ of Cohen's patients were AfroAmericans. Thus, racial differences may also contribute to the difference in prevalence of pain in CKD patients. Nevertheless, these data provide information on the prevalence of chronic MS pain in CKD patients.

The results of the present study indicate a correlation between the co-morbidity of hyperuricemia, the calcium $x$ phosphate product levels, and the co-morbidity of DM with chronic MS pain in CKD patients. This study raises the importance of uric acid control and gout prevention to decrease the possibility of chronic MS pain, thereby improving the quality of life in CKD patients. In addition, the study found that the calcium $\times$ phosphate product levels were an important factor for chronic MS pain, especially in CKD patients without hyperuricemia. Results of this study demonstrate that the calcium $\times$ phosphate product levels are an important laboratory parameter to consider while treating CKD patients with chronic MS pain and without hyperuricemia. Additionally, it was demonstrated that NSAID or Chinese herb use was not very common in CKD patients. Low prevalence of NSAID and Chinese herb use $(7.8 \%$ and $9.6 \%)$ may indicate either good patient education by healthcare professionals, or an underestimation or inaccurate reporting of NSAID and Chinese herb use by patients.
This study had several limitations. The information regarding pain relief agents was lacking. Furthermore, the colchicine use for gout relief in study patients was not collected. In addition, quality of life was not evaluated in this study. However, we believe that the results provide a solid basis for studies that will further explore these relationships. The ultimate goal should be a better understanding and treatment of chronic MS pain in CKD patients.

\section{Conclusion}

In summary, the present study demonstrated that chronic MS pain was independently and significantly associated with hyperuricemia and the calcium $\times$ phosphate product levels. In addition, in CKD patients with hyperuricemia, chronic MS pain was negatively, independently, and significantly associated with DM. However, in CKD patients without the co-morbidity of hyperuricemia, chronic MS pain was independently and significantly associated with the calcium $\times$ phosphate product levels.

\section{Competing interest}

The authors declare no financial competing or other competing interest.

\section{Authors' contributions}

$\mathrm{H}$-J $\mathrm{H}$ participated in data collection, statistical analysis and manuscript preparation; $\mathrm{C}-\mathrm{H}$ Y, $\mathrm{K}-\mathrm{H} \mathrm{H}$, and $\mathrm{C}-\mathrm{C} \mathrm{L}$ participated in statistical analysis; I-W W, M-J H, C-Y S, C-C C, Y-C C helped with data collection; M-F H, C-Y C, C-Y H, and $\mathrm{C}-\mathrm{J}$ T participated in data interpretation; M-S W participated in study design, coordination, and helped to draft the manuscript. All authors read and approved the final manuscript.

\section{Authors' information}

Heng-Jung Hsu and Chiung-Hui Yen are Co-first authors.

\section{Acknowledgments}

This study was supported by the Chang Gung Memorial Hospital Research Fund (CMRPG260363). The authors wish to express their deepest gratitude to all the patients who participated in this study.

\section{Author details}

'Department of Nephrology, Chang Gung Memorial Hospital, 222, Mai-Chin Road, Keelung 20401, Taiwan. ${ }^{2}$ The Graduate Institute of Clinical Medical Sciences, Chang Gung University Medical College, Taoyuan School of Medicine, Taipei, Taiwan. ${ }^{3}$ Chang Gung University, Taipei, Taiwan.

${ }^{4}$ Department of Pediatrics and Rheumatology, Taipei Medical University Hospital, Taipei, Taiwan. ${ }^{5}$ Laboratory of Epidemiology, Department of Health Care Management, Chang Gung University, Taipei, Taiwan. ${ }^{6}$ Department of Cardiology, Chang Gung Memorial Hospital, Keelung, Taiwan. ${ }^{7}$ Division of Nephrology, Taipei Medical University Hospital, Taipei, Taiwan. ${ }^{8}$ Department of Internal Medicine, Taipei Medical University, Taipei, Taiwan.

Received: 8 September 2012 Accepted: 18 December 2013 Published: 8 January 2014

\section{References}

1. Viktorsdottir O, Palsson R, Andresdottir MB, Aspelund T, Gudnason V, Indridason OS: Prevalence of chronic kidney disease based on estimated glomerular filtration rate and proteinuria in icelandic adults. Nephrol Dial Transplant 2005, 20(9):1799-1807.

2. Kovesdy CP, Mehrotra R, Kalantar-Zadeh K: Battleground: chronic kidney disorders mineral and bone disease-calcium obsession, vitamin $\mathrm{d}$, and binder confusion. Clin J Am Soc Nephrol 2008, 3(1):168-173.

3. Schiffrin EL, Lipman ML, Mann JF: Chronic kidney disease: effects on the cardiovascular system. Circulation 2007, 116(1):85-97. 
4. Singh AK, Szczech L, Tang KL, Barnhart H, Sapp S, Wolfson M, Reddan D: Correction of anemia with epoetin alfa in chronic kidney disease. $N$ Engl J Med 2006, 355(20):2085-2098

5. Evans RW, Manninen DL, Garrison LP Jr, Hart LG, Blagg CR, Gutman RA, Hull $A R$, Lowrie EG: The quality of life of patients with end-stage renal disease. N Engl J Med 1985, 312(9):553-559.

6. Mapes DL, Lopes AA, Satayathum S, McCullough KP, Goodkin DA, Locatelli F, Fukuhara S, Young EW, Kurokawa K, Saito A, et al: Health-related quality of life as a predictor of mortality and hospitalization: the dialysis outcomes and practice patterns study (DOPPS). Kidney Int 2003, 64(1):339-349.

7. McHorney CA, Ware JE Jr, Raczek AE: The MOS 36-item short-form health survey (SF-36): II. Psychometric and clinical tests of validity in measuring physical and mental health constructs. Med Care 1993, 31(3):247-263.

8. Davison SN, Jhangri GS: The impact of chronic pain on depression, sleep, and the desire to withdraw from dialysis in hemodialysis patients. J Pain Symptom Manage 2005, 30(5):465-473.

9. Fainsinger RL, Davison SN, Brenneis C: A supportive care model for dialysis patients. Palliat Med 2003, 17(1):81-82.

10. Cohen SD, Patel SS, Khetpal P, Peterson RA, Kimmel PL: Pain, sleep disturbance, and quality of life in patients with chronic kidney disease. Clin J Am Soc Nephrol 2007, 2(5):919-925.

11. Golan E, Haggiag I, Os P, Bernheim J: Calcium, parathyroid hormone, and vitamin D: major determinants of chronic pain in hemodialysis patients. Clin J Am Soc Nephrol 2009, 4(8):1374-1380.

12. Levey AS, Stevens LA: Estimating GFR using the CKD Epidemiology Collaboration (CKD-EPI) creatinine equation: more accurate GFR estimates, lower CKD prevalence estimates, and better risk predictions. Am J Kidney Dis 2010, 55(4):622-627.

13. Muirden KD: Community oriented program for the control of rheumatic diseases: studies of rheumatic diseases in the developing world. Curr Opin Rheumatol 2005, 17(2):153-156.

14. Collins SL, Moore RA, McQuay HJ: The visual analogue pain intensity scale: what is moderate pain in millimetres? Pain 1997, 72(1-2):95-97.

15. Cregler LL, Georgiou D, Sosa I: Left ventricular diastolic dysfunction in patients with congestive heart failure. J Natl Med Assoc 1991, 83(1):49-52.

16. Aletaha D, Neogi T, Silman AJ, Funovits J, Felson DT, Bingham CO 3rd, Birnbaum NS, Burmester GR, Bykerk VP, Cohen MD, et al: 2010 Rheumatoid arthritis classification criteria: an american college of rheumatology/ european league against rheumatism collaborative initiative. Ann Rheum Dis 2010, 69(9):1580-1588.

17. Dougados M, van der Linden S, Juhlin R, Huitfeldt B, Amor B, Calin A, Cats A, Dijkmans B, Olivieri I, Pasero G, et al: The european spondylarthropathy study group preliminary criteria for the classification of spondylarthropathy. Arthritis Rheum 1991, 34(10):1218-1227.

18. Chonchol M, Shlipak MG, Katz R, Sarnak MJ, Newman AB, Siscovick DS, Kestenbaum B, Carney JK, Fried LF: Relationship of uric acid with progression of kidney disease. Am J Kidney Dis 2007, 50(2):239-247.

19. Badve SV, Brown F, Hawley CM, Johnson DW, Kanellis J, Rangan GK, Perkovic $\mathrm{V}$ : Challenges of conducting a trial of uric-acid-lowering therapy in CKD. Nat Rev Nephrol 2011, 7(5):295-300.

20. Schlesinger N, Norquist JM, Watson DJ: Serum urate during acute gout. J Rheumatol 2009, 36(6):1287-1289.

21. Sulkova S, Fortova M, Valek M, Svara F: [Renal bone disease]. Vnitr Lek 2003, 49(5):403-408.

22. Cozzolino M, Dusso AS, Slatopolsky E: Role of calcium-phosphate product and bone-associated proteins on vascular calcification in renal failure. J Am Soc Nephrol 2001, 12(11):2511-2516.

23. Suppiah $\mathrm{R}$, Dissanayake $\mathrm{A}$, Dalbeth $\mathrm{N}$ : High prevalence of gout in patients with Type 2 diabetes: male sex, renal impairment, and diuretic use are major risk factors. N Z Med J 2008, 121(1283):43-50

24. Liu Q, Gamble G, Pickering K, Morton S, Dalbeth N: Prevalence and clinical factors associated with gout in patients with diabetes and prediabetes. Rheumatology (Oxford) 2012, 51(4):757-759.

25. Choi HK, De Vera MA, Krishnan E: Gout and the risk of type 2 diabetes among men with a high cardiovascular risk profile. Rheumatology (Oxford) 2008, 47(10):1567-1570.

26. Lai HM, Chen CJ, Su BY, Chen YC, Yu SF, Yen JH, Hsieh MC, Cheng TT, Chang SJ: Gout and type 2 diabetes have a mutual inter-dependent effect on genetic risk factors and higher incidences. Rheumatology (Oxford) 2012, 51(4):715-720.
27. Leaverton PE, Peregoy J, Fahlman L, Sangeorzan E, Barrett JP Jr: Does diabetes hide osteoarthritis pain? Med Hypotheses 2012, 78(4):471-474.

28. DeVon HA, Penckofer S, Larimer K: The association of diabetes and older age with the absence of chest pain during acute coronary syndromes. West J Nurs Res 2008, 30(1):130-144

29. Pham PC, Dewar K, Hashmi S, Toscano E, Pham PM, Pham PA, Pham PT: Pain prevalence in patients with chronic kidney disease. Clin Nephrol 2010, 73(4):294-299.

doi:10.1186/1471-2369-15-6

Cite this article as: Hsu et al:: Factors associated with chronic musculoskeletal pain in patients with chronic kidney disease. BMC Nephrology 2014 15:6.

\section{Submit your next manuscript to BioMed Central and take full advantage of:}

- Convenient online submission

- Thorough peer review

- No space constraints or color figure charges

- Immediate publication on acceptance

- Inclusion in PubMed, CAS, Scopus and Google Scholar

- Research which is freely available for redistribution 